\title{
A AVALIAÇÃo DA PÓS-GRADUAÇÃo E A SUA RELAÇÁO COM A PRODUÇÃO CIENTÍFICA: DILEMAS ENTRE A QUALIDADE E A QUANTIDADE
}

\author{
THE EVALUATION OF POSTGRADUATE AND ITS RELATIONSHIP \\ WITH CIENTIFIC PRODUCTION: DILEMS BETWEEN QUALITY AND \\ QUANTITY
}

\author{
Altair Alberto Fávero \\ Pós-Doutor (Bolsista Capes) pela Universidad Autónoma del Estado de México (UA- \\ EMéx), Doutor em Educação (UFRGS). Universidade de Passo Fundo, Brasil \\ Lates: http://lattes.cnpq.br/5866881378328643 \\ altairfavero@gmail.com \\ Evandro Consaltér \\ Doutorando em Educaçáo (Bolsista CAPES) pela Universidade de Passo Fundo. Mes- \\ tre em Educação (Bolsista CAPES) pelo programa de Pós-graduação em Educação da \\ Universidade de Passo Fundo. Universidade de Passo Fundo (UPF), Brasil. \\ Lates: http://lattes.cnpq.br/5349128185364838 \\ evandroconsalter@gmail.com \\ Carina Tonieto \\ Instituto de Educação, Ciência e Tecnologia do Rio Grande do Sul/IFRS/Campus de Ibirubá \\ Doutora em Educação (UPF), Mestre em Educação (UPF/Bolsis- \\ ta Capes). Universidade de Passo Fundo (UPF), Brasil. \\ Lates: http://lattes.cnpq.br/9429620134345330 \\ tonieto.carina@gmail.com
}

Resumo: O presente texto é fruto de uma pesquisa de cunho qualitativo e desenvolvese a partir da triangulação de fontes bibliográficas e documentais. O método analítico é utilizado para estabelecer o olhar crítico e reflexivo sobre os dados apurados. O objetivo é responder ao seguinte questionamento: Como a avaliação da pós-graduação é influenciada e impactada por processos e indicadores externos à universidade? $\mathrm{O}$ texto está estruturado em três seçóes. Na primeira, discutimos como o produtivismo acadêmico tem impactado a gestão e a organização interna dos programas de pós-graduação. $\mathrm{Na}$ segunda seção, procuramos identificar como essa lógica produtivista tem fomentado o mercado das chamadas "revistas predatórias", que se aproveitam dessa necessidade de publicação dos pesquisadores para lucrar e estabelecer um "mercado de publicaçôes". Por fim, discutimos a necessidade de um equilíbrio entre qualidade e quantidade com a finalidade de pensar e reforçar a relevância social da pesquisa e a consolidação de políticas de avaliação da pós-graduaçáo que possam garantir essa equidade necessária ao pleno exercício dos pesquisadores. Concluímos que avaliar é um passo importante para o aprimoramento da pós-graduação, no entanto, submetida aos ditames do gerencialismo, 
produtividade e performatividade produz efeitos nefastos à pesquisa, aos professores/ pesquisadores e aos processos formativos.

Palavras-chave: Avaliação. Pós-graduação. Qualidade. Produtividade.

Abstract: This text is the result of qualitative research and is developed from the triangulation of bibliographic and documentary sources. The analytical method is used to establish a critical and reflexive look at the data. The objective is to answer the following question: How is postgraduate evaluation influenced and impacted by processes and indicators external to the university? The text is structured in three sections. In the first part, we discuss how academic productivism has impacted the management and internal organization of postgraduate programs. In the second section, we seek to identify how this productivist logic has fostered the market for so-called "predatory magazines", which take advantage of this need to publish researchers to profit and establish a "publishing market". Finally, we discuss the need for a balance between quality and quantity in order to think about and reinforce the social relevance of research and the consolidation of postgraduate evaluation policies that can guarantee this equity necessary for the full exercise of researchers. We conclude that the evaluation is an important step for the improvement of the postgraduate, however, subjected to the dictates of managerialism, productivity and performativity produces harmful effects on research, teachers / researchers and training processes.

KeYwords: Evaluation. Postgraduate studies. Quality. Productivity.

\section{Introduçáo}

A avaliação da pós-graduação no Brasil assume, a partir da década de 1990, um modelo fortemente caracterizado pelo que, mais tarde, autores como Bianchetti, Zuin e Ferraz (2018) e Machado, Grosch e Santos (2017) dentre outros, chamarão de "produtivismo acadêmico". É justamente nesta época que a Coordenação de Aperfeiçoamento de Pessoal de Nível Superior (CAPES) passou a adotar um tempo médio de titulaçáo de dois anos para o mestrado e de quatro anos para o doutorado, acompanhada de uma avaliação dos programas fortemente impactada pela mensuração ou quantificação de "produtos". Esse modelo avaliativo tem influenciado diretamente na organização interna dos programas de pós-graduação, na vida dos pesquisadores e na grande rede de periódicos científicos.

No tangente à organizaçáo interna dos programas, a exigência de metas e a quantificação das produçôes docentes tem acompanhado o cotidiano dos pesquisadores e gestores da pós-graduação. $\mathrm{O}$ reconhecimento 
pelo Ministério da Educação - MEC e o acesso aos editais de pesquisa passam, sobretudo, pelos conceitos atribuídos aos programas por meio das avaliaçôes da Capes, fazem com que a gestão dos programas se oriente a partir deste sistema. Consequentemente, a pressão por metas e pela publicação em extratos qualificados tem se torando constante na vida profissional dos docentes de pós-graduação. Zuin e Bianchetti (2015) relatam que tamanha pressão tem originado uma série de expressóes jocosas como "Lattes, Lattes meu, existe alguém mais produtivo do que eu"; "artigos passados não movem o Lattes”.

Além desses fatores internos aos programas, a pressão por produção científica e publicaçôes, têm gerado impactos externos. $\mathrm{O}$ chamado mercado das revistas e editoras predatórias cresce a passos largos, ano após ano, justamente transformando em um negócio obscuro e lucrativo a necessidade de publicaçóes pelos docentes de pós-graduação. Esse mercado inclui editoras que garimpam artigos em anais de eventos para publicação de e-books e periódicos que enviam convites para os pesquisadores publicarem em seus volumes, tudo sem muito rigor metodológico e científico e sob a regra do "pagou, publicou".

Diante deste cenário, desenvolvemos este texto com o objetivo de responder ao seguinte questionamento: Como a avaliação da pós-graduação é influenciada e impactada por processos e indicadores externos à universidade? Para elucidar possíveis respostas, utilizamos como referencial os estudos de Bianchetti, Zuin e Ferraz (2018), Zuin e Bianchetti (2015), entre outros renomados pesquisadores da temática. O texto está estruturado em três seçôes. Na primeira, discutimos como o produtivismo acadêmico tem impactado a gestão e a organização interna dos programas de pós-graduação. $\mathrm{Na}$ segunda seção, procuramos identificar como essa lógica produtivista tem fomentado o mercado das chamadas "revistas e editoras predatórias", que se aproveitam dessa necessidade de publicação dos pesquisadores para lucrar e estabelecer um "mercado de publicaçóes". Por fim, discutimos a necessidade de um equilíbrio entre qualidade e quantidade com a finalidade de pensar e reforçar a relevância social da pesquisa e a consolidação de políticas de avaliação da pós-graduação que possam garantir essa equidade necessária ao pleno exercício dos pesquisadores. 


\section{O produtivismo acadêmico e suas implicaçóes na organização interna dos programas de pós-graduação}

Os programas de pós-graduação estão submetidos a lógica da regulação e do produtivismo. Tais constatações são inegáveis e fazem parte do cotidiano das instituiçóes e dos sujeitos que nelas atuam (ANDRADE, CASSUNDÉ, BARBOSA, 2019; SUETH, PAULA, 2018; BIANCHETTI, ZUIN, FERRAZ, 2018; MACHADO, GROSCH, SANTOS, 2017; ZUIN, BIANCHETTI, 2015; TREIN, RODRIGUES, 2011). A corrida desenfreada pela publicação não é sinônimo de qualidade, isto é, a quantidade não é diretamente proporcional à qualidade e por uma razão muito simples: a publicação entendida como resultado de rigorosos processos de investigaçáo e avaliação por pares, náo funciona aos moldes da produção em série. Não se trata de produção de mercadorias (TREIN, RODRIGUES, 2011), mas de pesquisas que seguem uma série de requisitos teóricos e metodológicos para serem consideradas científicas, assim como, capacidade criativa, tempo e dedicação dos pesquisadores.

Vale registrar, também, os trâmites institucionais, burocráticos e de financiamento a que estấo submetidas as pesquisas desenvolvidas na academia. Desse modo, cada pesquisa precisa dar conta antes, durante e depois de sua operacionalização de uma série de requisitos que a legitimam como pesquisa científica confiável e responsável. Esses elementos conferem ao processo de produção da pesquisa acadêmica um tempo diferente daquele da produção por repetição. Além disso, o processo produtivo da pesquisa não é reprodução, é produçấo e como tal precisa dar conta de dimensóes únicas e exclusivas que lhe conferem o status de novidade e relevância, do contrário ficar-se-ia apenas replicando pesquisas já realizadas.

A não replicação, por sua vez implica, na busca pela descoberta e pela releitura de determinados fenômenos. É essa busca pelo acréscimo qualitativo que gera produção do conhecimento e que é o norte dos programas de pós-graduaçáo aliado a formação de pesquisadores que, aliás, também não acontece em série, obviamente por se tratar de um processo formativo humano que exige maturação teórico-metodológica e pessoal. A notoriedade dos resultados das pesquisas e dos pesquisadores não acontece pela quantidade, mas pela qualidade do trabalho e de seus resultados, o que acarreta que a corrida desenfreada pela publicação, 
mediante a pressão da quantidade, tende a banalização da pesquisa, a superficialidade e a repetição.

Nesse cenário de corrida pela quantidade, tentando garantir o rigor necessária à produção da pesquisa e a formação do pesquisador, os programas de pós-graduaçáo se movimentam e se rearranjam para dar conta das demandas impostas. Esses arranjos incidem diretamente na pressão por produção e publicação direcionada aos docentes e discentes, já que sob a égide do produtivismo e rankeamento, conhecimento científico valorizado é aquele que pode ser trocado (TREIN, RODRIGUES, 2011).

Aos docentes cabe, além de pesquisar e publicar, ministrar aulas na graduação e pós-graduação; orientar estudantes e/ou bolsistas; coordenar grupos de pesquisa; participar da gestão, comissóes, colegiados, bancas; integrar comitês científicos; ser avaliador de periódicos e editor; participar e organizar eventos acadêmicos; enfim, uma séria de atividades da vida acadêmica que também imersa na lógica da produtividade, exigem tempo, dedicação e esforço. $\mathrm{O}$ acúmulo de atividades de docência, pesquisa, extensão e gestão imprime aos docentes um ritmo de trabalho que exige dedicação em tempo integral, ou que implica na abdicação de boa parte de sua vida pessoal, para dar conta das demandas da vida acadêmica, condição já naturalizada na rotina dos docentes (ANDRADE, CASSUNDÉ, BARBOSA, 2019). A rotina extenuante associada às condiçóes precárias de trabalho e pressão intensa, tem levado os docentes a ver a profissão com descontentamento e a terem problemas de saúde (BIANCHETI, MACHADO, 2007; BIANCHETTI, ZUIN, FERRAZ, 2018; ANDRADE, CASSUNDÉ, BARBOSA, 2019).

Entretanto, tais condiçôes são relegadas a segundo plano e a gestão dos programas tende a ser rígida para dar conta das exigências, que se negligenciadas, implicam diretamente no conceito dos programas, o que acarreta, por sua vez em outras consequências, como por exemplo no número de bolsas para os discentes. A estratégia adotada pelos programas segue a lógica do produtivismo, ou seja, gerir a partir de planilhas de indicadores quantitativos acompanhando de perto os produtos gerados pelos docentes e discentes. Desse modo, a lógica do controle e gerencialismo quantitativo é um caminho eficiente e aos docentes improdutivos cabe o descredenciamento. A lógica do gerencialismo apesar de perversa é uma estratégia de sobrevivência, 
já que o não cumprimento das métricas estabelecidas pelos órgãos reguladores incide de modo direto na continuidade dos programas.

Associado ao cenário docente está o discente. Os futuros pesquisadores aprendem a lógica da pressão pela publicação desde muito cedo, isto é, já nos processos seletivos para ingresso nos programas, os quais consideram como um dos critérios as publicaçôes do candidato. E tal pressão, continua durante o período de formação, já que a produção discente também é um dos indicadores considerados na avaliação do programa. Nesse cenário, a parceria entre orientandos e orientadores é uma estratégia adotada que beneficia a ambos e é valorizada pela avaliação externa; assim como, em determinados programas é exigido dos acadêmicos, como condição para expedição do diploma, a comprovação de submissão de artigo em revista indexada e de qualidade reconhecida na área, conforme mostrou o estudo de Andrade, Cassundé e Barbosa (2019).

A lógica da pressão produtivista não poupa os discentes, futuros pesquisadores, pois a conclusão do curso está atrelada a tentativa de publicação, submetida a uma lógica perversa, na qual a revista indexada e de qualidade reconhecida na área, na grande maioria das vezes, não tem interesse pela publicação de trabalhos de futuros mestres e doutores, pois o seu Qualis está associado, dentre outros fatores, à titulação dos professores que nela publicam. Resta aos futuros pesquisadores, ainda sem seus títulos, a tentativa, num contexto em que os periódicos com os melhores Qualis não tem interesse em pesquisas de futuros doutores; os com Qualis intermediários querem subir na escala, para isso precisam de publicaçóes de doutores e, portanto, também, não têm interesse pelos quase mestres e doutores. A submissão, certamente, não implica em aceitação e pode ser usada como uma ferramenta de avaliação, ou seja, identificar se o discente aprendeu que pesquisar é sinônimo de publicar e que esta é a dinâmica da vida acadêmica. Conforme apontado pelo estudo de Andrade, Cassundé e Barbosa (2019), o negócio é ter bons discentes, isto é, selecionar na entrada para garantir publicaçôes durante e depois da conclusão do curso.

A seleção na entrada, no entanto, privilegia o acesso de determinado perfil de discente aos programas de pós-graduação, isto é, aqueles que conseguiram ou tiveram o privilégio durante a sua formaçáo de usufruir da inserção na pesquisa. E aqueles que não tiveram esse privilégio por uma série de fatores culturais, sociais e econômicos, podem desejar o acesso a um curso 
de mestrado e doutorado? E os que fazem suas graduaçóes e mestrados em condiçôes precárias de tempo e de recursos financeiros? A lógica do produtivismo não poupa ninguém e a cultura da performatividade (MOREIRA, 2009) é sagaz, rígida e disciplinadora do tempo, do espaço e dos produtos.

A seletividade produtivista está associada ao tempo máximo para defesa de dissertaçôes e teses, de modo a penalizar os programas pelo não cumprimento dos prazos. Diante dessa engrenagem, trabalhos de conclusão são apressados para dar conta dos prazos e o protocolo de submissão de artigo (oriundo da dissertaçáo ou tese) adquire o status de documento táo importante ou mais importante que a própria dissertação ou tese. Tudo gira em torno das publicaçóes e o "desempenho é a medida da produtividade” (MOREIRA, 2009, p. 32), reafirmando o perfil de discente desejado pelos programas que logicamente não é o de iniciante na pesquisa.

Como fica a qualidade dos processos formativos do futuro pesquisador e a sua inserção na docência? Afinal de contas, a formação em nível de pós-graduação não tem dentre os seus objetivos formar o professorpesquisador? Este não é o ponto mais importante da pauta, apesar de ser a porta de entrada dos pesquisadores nas instituiçóes de educaçáo superior acontecer pela docência, ou seja, são contratados para serem professores e pesquisadores. A questáo da qualidade da docência, tempo e energia dedicado a ela nos programas é pauta para outro artigo. No entanto, cabe a denúncia de mais uma falácia da lógica produtivista na acadêmica: ser bom pesquisador é igual a ser bom professor.

Esse cenário desenfreado comandado pela performatividade (MOREIRA, 2009) e pelo mantra "publique, apareça ou pereça" (ZUIN, BIANCHETTI, 2015, p. 739) alimenta um outro nicho de mercado (para ser fiel ao vocabulário) o das revistas predatórias, os quais sabem usar com maestria as nuances da competividade acadêmica e cenário de espetacularização das publicaçóes e seus atores. Deste cenário trataremos a seguir.

\section{As revistas predatórias e o mercado de publicaçóes}

A lógica do produtivismo acadêmico, em cujo leque estáo incluídos a quantidade de publicaçôes, a pressão para publicar, os meios para tal e as estratégias lícitas (outras nem tanto), para a "produção" ser veicula- 
da (ZUIN; BIANCHETTI, 2015), tem influenciado no surgimento de um mercado obscuro e fraudulento, o das revistas e editoras predatórias. Oliveira (2017) lista uma série de características típicas dessas corporaçôes: i) envio de lotes de e-mails com convite para submissão de artigos; ii) taxa de aceitação muito elevada; iii) publicação extremamente rápida; iv) exigência de transferência de direitos autorais antes da aceitação; v) limitação na supervisão ou editoração; vi ) revisão por pares deficiente ou inexistente; vii) alegações falsas sobre indexação e fator de impacto; viii) inserção de nomes no corpo editorial sem autorização; ix) desconsideração dos pedidos de retirada de tramitação (OLIVEIRA, 2017).

Para Oliveira (2017), o crescimento acentuado dessas publicações que seguem a lógica do "pagou, publicou" originou-se, sobretudo, a partir da política do open access. As publicaçóes de acesso livre objetivam democratizar as publicaçóes de artigos de qualidade, avaliados criteriosamente com todo rigor científico, como é o caso da página da Taylor \& Francis, um dos maiores grupos editoriais do mundo acadêmico. Oliveira (2017) destaca que, nesses casos, o custeio no sistema open access oficial se dá pelo pagamento de taxas de publicação pelos autores, instituiçóes ou agências financiadoras. Por outro lado, sob a camuflagem do open access, as revistas e editoras predatórias cobram taxas para publicar, rapidamente e com pouco rigor analítico, artigos com qualidade duvidosa. É o mercado das publicações e da lucratividade. Esses publishers, segundo Oliveira (2017, p. 4), também "atuam em outras vertentes relacionadas ao universo científico e acadêmico, tais como na publicação de livros e produção de eventos".

A partir de uma lista publicada pelo professor da Universidade do Colorado, Jeffrey Beall (2013), especialista em rastrear revistas e editoras predatórias ${ }^{1}$, Oliveira (2017) acompanhou o crescimento, nos últimos anos, desses grupos editorais e periódicos. As imagens das figuras 1 e 2 mostram os gráficos que estampam tal crescimento.

Geralmente, essas revistas ou editoras procuram os pesquisadores a partir de trabalhos completos publicados em anais de eventos, onde comumente constam informaçóes de contato e instituição dos autores. Todavia, publicar um trabalho divulgado em anais de eventos implica na sua não inediticidade, requisito básico para o aceite em uma revista científica de qualidade. Este fato pode ser observado nas figuras 3, 4 e 5, onde dois 


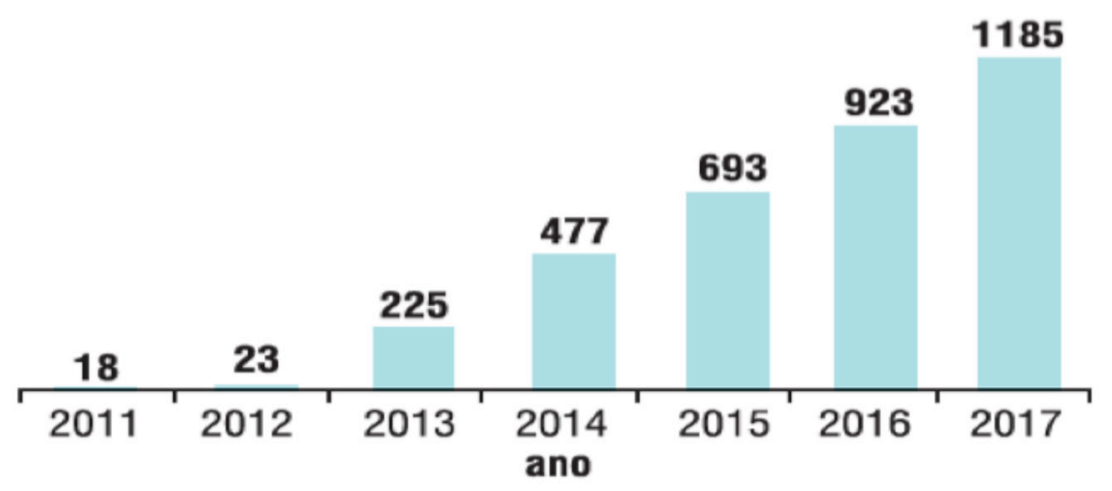

Figura 1: Gráfico do número de editoras predatórias de 2011 a 2017 Fonte: Oliveira (2017, p. 5).

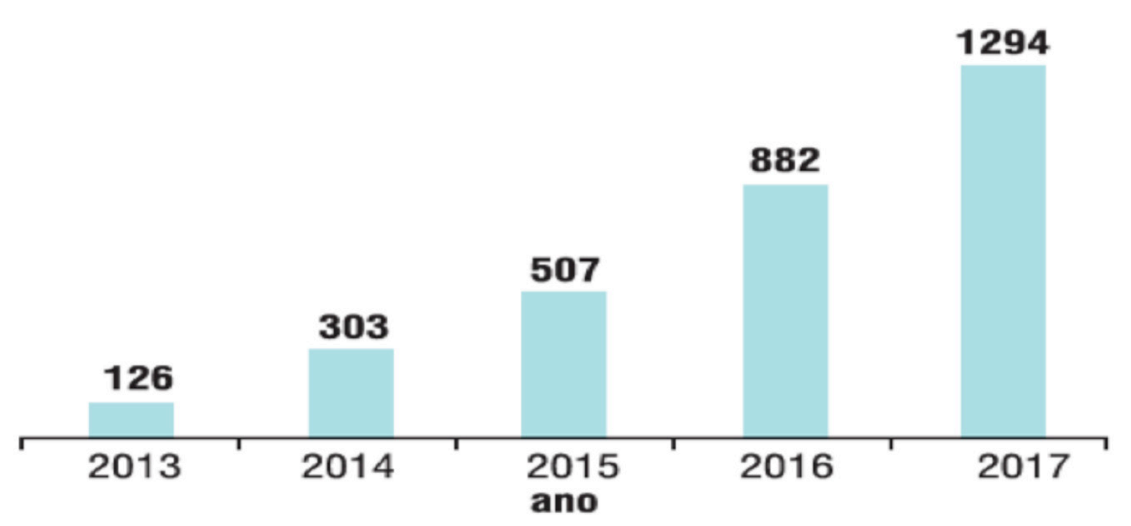

Figura 2: Gráfico do número de revistas predatórias independentes de 2011 a 2017

Fonte: Oliveira (2017, p. 5).

diferentes meios de publicação, um nacional (e-book) e um internacional (journal), nos enviaram proposta para publicação do mesmo trabalho, desconsiderando ele já estar publicado nos anais de um evento. O primeiro, inclusive, estipula o valor de $\mathrm{R} \$ 386,00$ (trezentos e oitenta e seis reais), para dar andamento à publicaçáo do texto como capítulo do e-book. No email, destaca o "open acess" do livro e a possibilidade de obtenção de Qualis 
L3 no extrato de avaliaçáo da Capes, o que comprovaria a relevância da obra para o meio acadêmico.

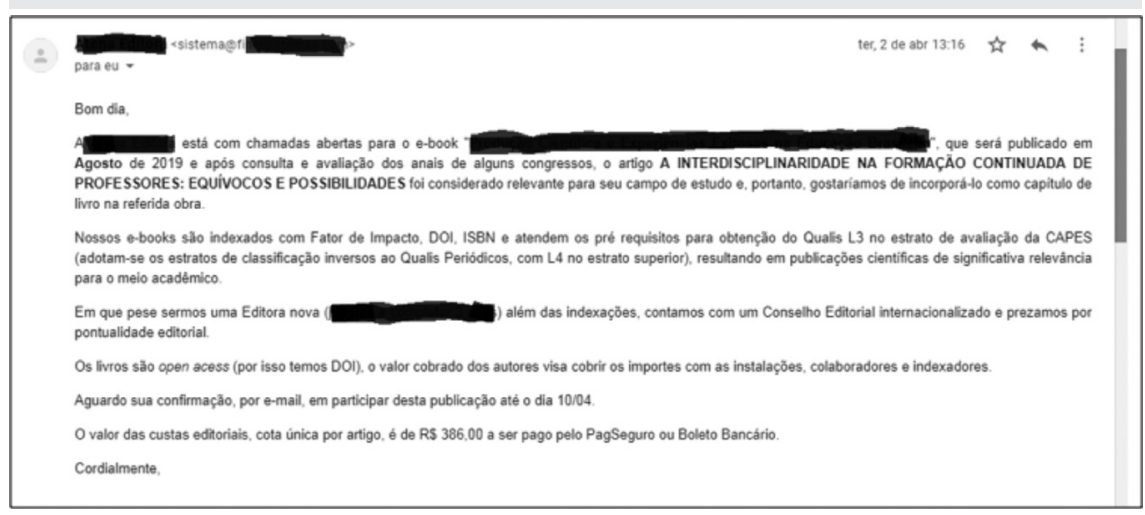

Figura 3: Mensagem eletrônica para publicação de artigo em e-book Fonte: Elaborada pelos autores.

O mesmo artigo também serve de porta para convite de um journal, com o objetivo de envio de artigo em inglês para integrar um de seus volumes. No mesmo e-mail, os editores também convidam os autores para integrarem o corpo editorial do periódico. Todas essas peculiaridades assemelham-se muito com o que Oliveira (2017) identifica como características típicas de corporaçóes predatórias no meio acadêmico. Além disso, consultando as diretrizes para os autores no referido journal, uma das normas para a publicação estabelece que, como de costume, se o artigo for aceito, o autor deverá pagar uma taxa de processamento. Os valores não são especificados. (Figura 4)

Resolvemos responder o e-mail questionando os editores se poderíamos enviar a versão em língua inglesa do artigo completo já publicado nos anais, conforme mostra a imagem da figura 5.

Em pouco tempo, obtivemos a resposta positiva para o questionamento (Figura 6). Esta situação deixa claro o viés mercadológico do periódico e o seu interesse em lucrar com publicaçóes em detrimento de disseminar com rigor e qualidade produçóes científicas inéditas. Conforme Zuin e Bianchetti (2015), podemos dizer que é mais um periódico que se encaixa na lógica do "pagou, publicou". 


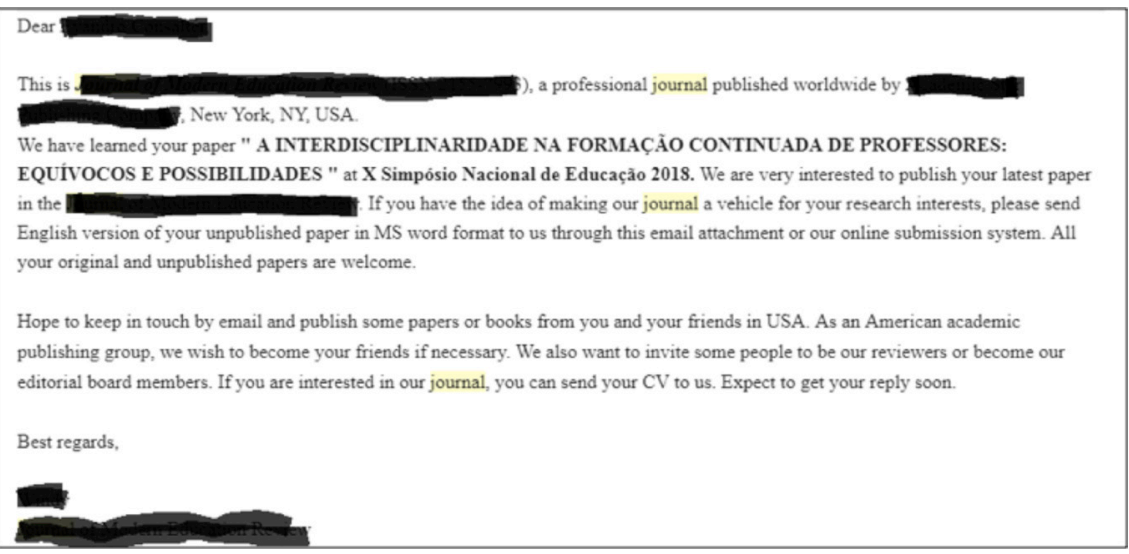

Figura 4: Mensagem eletrônica do journal para publicação de artigo Fonte: Elaborada pelos autores.

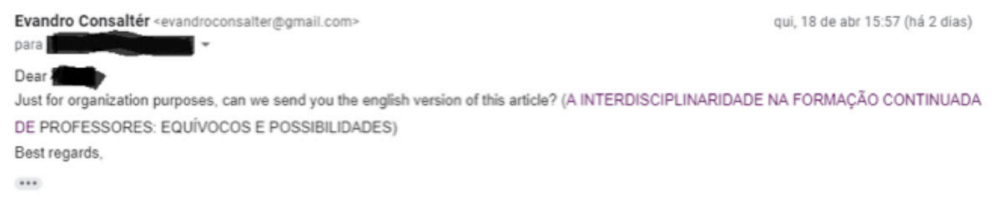

Figura 5: Mensagem eletrônica com questionamento ao journal Fonte: Elaborada pelos autores.

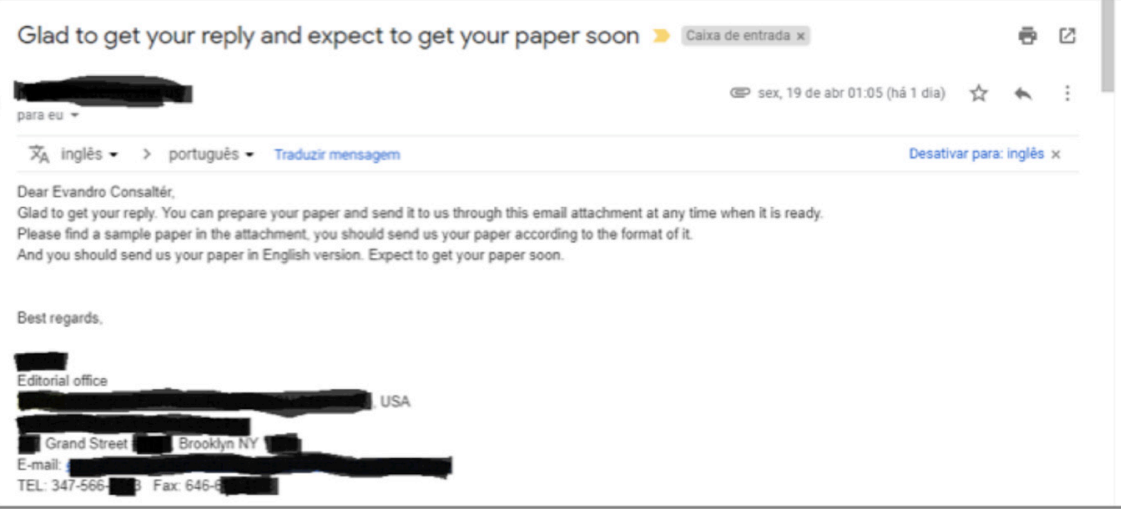

Figura 6: Mensagem eletrônica com a resposta do journal

Fonte: Elaborada pelos autores. 
Diante do exposto e dos convites recebidos, resolvemos fazer um teste e submeter o mesmo artigo, já publicado em anais de evento, para uma conceituada revista brasileira (Qualis Capes B1 - Educaçáo) de acesso livre. Após algum tempo, recebemos como retorno o não aceite para publicação. Como justificativa, a revista aponta que após avaliação por sua equipe de pareceiristas, foi identificada a publicação do artigo em anais de um congresso, o que implica no desacordo ao requisito de ineditismo. Esta constatação, segundo a revista, condiciona o cancelamento da submissão. $\mathrm{Na}$ imagem da figura 7 consta o registro do não aceite para publicação.

Para: Altair Favero caltaiffavero@gmail cem?

Prezado.

Boa tarde.

Em avaliação por equipe de pareceristas foi identificada a publicação do artigo em anais de um congresso fhttp/leducere bruc com brtat

guivolodi2017724220_11825 pdf), em desacordo com o requisito de ineditismo.

Sendo assim, a submissão é necessariamente cancelada.

Novamente, pedimos desculpas pela demora no retorno. Com o fim da greve no inicio deste ano. a revista está retomando a normalidade de seus processos e esperamos contar com suas contribuiçðes em breve.

Figura 7: Mensagem eletrônica como o parecer da revista

Fonte: Elaborada pelos autores.

Convites para publicação como estes reforçam a necessidade de se desenvolver uma cultura de alerta às práticas editoriais duvidosas, considerando que a participação brasileira em publicaçóes de natureza predatória tem aumentado muito nos últimos anos. Conforme dados divulgados pelo site Preda Qualis, criado em 2017 por docentes da USP, Unesp e UFABC, existem hoje 485 periódicos com práticas editoriais duvidosas sendo usados por professores, pesquisadores e pós-graduandos de universidades brasileiras. O objetivo do site é o de: identificar periódicos potencialmente fraudulentos listados pelo Sistema Qualis-Capes; estimar a proporção destes periódicos na base Qualis; Estimar a chance destes periódicos serem detectados pelo sistema Qualis ${ }^{2}$.

A metodologia utilizada para se chegar a esses números considera a compilação de uma lista de periódicos potencialmente predatórios com- 
binando duas bases: lista de periódicos publicados pela editora OMICS, uma das maiores editoras reconhecidamente predatórias e a lista de periódicos com práticas questionáveis criada pelo professor Jeffrey Beall. Após a compilaçáo dos dados, o site realizou o cruzamento com os títulos no Qualis ${ }^{3}$, classificação de todos os periódicos por cada área, para a avaliação dos programas no quadriênio 2013-2016. A imagem da figura 8 mostra o número de periódicos considerados predatórios, através desta metodologia, com publicaçóes de pesquisadores brasileiros.

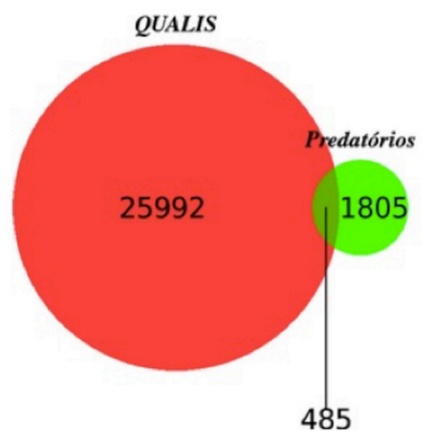

Figura 8: Gráfico dos periódicos predatórios com publicaçóes brasileiras Fonte: https://predaqualis.netlify.com/

Em análise dos dados apurados, o Preda Qualis destaca que dos 485 periódicos "potencialmente predatórios", $67 \%$ foram classificados nos estratos A e B do Qualis, em vez de serem listados no nível C, destinado às publicaçóes consideradas de menor qualidade. Segundo os criadores do site, esse fato se deve ao fato de que "há uma grande vulnerabilidade do sistema de avaliação da Capes à invasão por este tipo de publicação”. Nesse sentido, o Preda Qualis faz algumas considerações sobre estes títulos potencialmente predatórios. Primeiro, afirma que a lista compilada "não é uma palavra final e está em constante revisão, devendo ser usada como subsídio para avaliaçóes caso a caso e a critério dos autores e instituiçôes". Além disso, reitera "que apresentamos estes resultados na intenção de contribuir para o aperfeiçoamento dos critérios de avaliação dos programas de pós-gradução e do sistema QUALIS”. 
Outro apontamento do Preda Qualis é sobre o fato de que "um artigo ser publicado em uma revista potencialmente predatória não significa que este artigo seja de má qualidade. Um dos prejuízos causados pelos periódicos predatórios é justamente o de afetar a credibilidade de tais artigos". Por isso, questionar os critérios de qualidade utilizados para a classificação e ranking do sistema Qualis-Capes, assim como, denunciar os periódicos predatórios consiste numa tentativa de denunciar e combater essa nefasta lógica do produtivismo acadêmico assentado sob as bases da performatividade.

\section{O equilíbrio entre qualidade e quantidade na produçáo científica}

O instigante e provocativo ensaio "Inimigos da esperança: publicar, perecer e o eclipse da erudição”, Waters (2006), editor da Harvard University Press, analisa o problema do produtivismo acadêmico sob o ponto de vista do público, da sociedade, dos professores universitários e dos bibliotecários. Trata-se de um grito de alerta proferido por um renomado conhecedor do assunto, profundamente dedicado à preservaçáo da nobreza da produção acadêmica, que ao observar o atual cenário da produçáo científica percebe que a mesma corre sérios riscos de participar do processo de superficialização quantitativa proporcionada pelo produtivismo acadêmico. Seus argumentos e análises ajudam a focar nosso olhar na importância do equilíbrio entre qualidade e quantidade na produção científica, nem sempre observada pelos processos de avaliação em que são submetidos os pesquisadores envolvidos.

Dentre os diversos aspectos analisados, Waters (2006, p.19) ressalta o "crescimento da classe administrativa" na nova cultura acadêmica "construída para estar em sincronia com o mercado", em que as humanidades, por exemplo, perdem cada vez mais seu espaço. "O surgimento da doutrina neoliberal”, escreve Waters (2006, p.24), “despertou, entre os contribuintes, a noção de que todos os serviços sociais devem ser privatizados" e com isso a ideia de que tudo tem de ser quantificado e resultar em produtividade. Temos uma infinidade de produções de qualidade duvidosa em que as "boas produçóes se perdem na enxurrada de produçóes de baixa qualidade". "O problema”, diz Waters (2006, p.25) "é a insistência na produtividade, sem 
a menor preocupação com a recepção do trabalho" e com isso a perda do equilíbrio entre "produção e recepção". Tal desequilíbrio resulta na explosão de produçóes sem atentar para um olhar cuidadoso sobre a qualidade do que é produzido. Criam-se burocracias e regras para avaliar veículos de produção que instituem padrões que passam determinar a classificação do que é produzido. Assim, muitas vezes, as comissóes que avaliam a indicação ou promoção de um candidato para uma determinada função acadêmica, examinam mais os nomes das revistas citadas em seu currículo do que as ideias contidas nos artigos que tal candidato escreveu. Temos aí um exemplo típico do desequilíbrio entre quantidade e qualidade.

O domínio do administrativo sobre o acadêmico na publicação das revistas é fartamente questionado e criticado por Waters (2006, p.31-32), pois "de alguma forma nós terceirizamos o processo de avaliaçáo de nossos colegas, relegando-o a essas revistas de elite". Essa "terceirização" é motiva$\mathrm{da}$, muitas vezes, pelo medo de comprometer-se em avaliar o trabalho dos colegas ou por se sentir "incapaz de julgar o trabalho de seus pares”. Assim, assistimos a um intenso mecanismo que prima mais pela quantidade ou por uma qualidade formal das avaliaçóes do que propriamente por um processo de avaliação qualitativa.

No que diz respeito especificamente a pós-graduação, ressaltamos que a avaliação se configura como elemento de grande relevância para a estruturação de todo o sistema. De fato, o processo de implantação e expansão da pós-graduação no Brasil, bem como o planejamento estatal, os efeitos de regulação, fomento e modelação instituídas pelas agências federais tem na avaliação um dos seus principais pilares. Na visão de Oliveira e Fonseca (2010, p.17-18, grifo dos autores) "o aperfeiçoamento do modelo de avaliação Capes", foram responsáveis por "medir o desempenho dos programas/cursos, incentivar a produtividade docente e discente, ampliar a pesquisa científica e, supostamente, criar um 'padrão mínimo de qualidade', visando obter a melhoria dos programas/cursos”.

Ao analisar a trajetória da pós-graduação no Brasil, não resta dúvida que tanto a Capes quanto o CNPq contribuíram enormemente na formação de pesquisadores e docentes de alto nível para as Instituiçôes de Ensino Superior (IES). Como destacam Oliveira e Fonseca (2010, p.26-28) "a Capes e o CNPq foram agências criadas em 1951" e tiveram como principal objetivo "a implantação de um projeto nacional de desenvolvimento". Para tanto 
era necessária "a formação de recursos humanos", "a promoção da cooperação científica internacional”, o acesso e a divulgação da produção científica dos pesquisadores. Tanto "o financiamento quanto a avaliação permanente da pós-graduação garantiram à Capes um papel preponderante na política e nos rumos da pós-graduação no Brasil", incentivando a ideia de produtividade crescente como elemento discriminador no ranking avaliativo dos Programas/Cursos de Mestrado e Doutorado. Entretanto, cabe questionar: a produtividade crescente dos pesquisadores induzida pelos formatos avaliativos da Capes tem contribuído para melhorar a qualidade da produção?

Nas consideraçóes de seu ensaio, Oliveira e Fonseca (2010, p.45-46) destacam que "a análise da pós-graduação e de sua avaliação no Brasil, em que pese sua relevância, legitimidade, dimensão, expansão e desempenho, mostram uma maior ênfase em índices comparativos em âmbito nacional e internacional, tendo em vista a performance ou produtividade do país". No entanto, a forma como a Capes tem monitorado a pós-graduação se traduz numa "avaliação centralizadora, contábil, operacional, de resultados tecnicistas, performática, intensificadora do trabalho, ou melhor, de cunho estritamente pragmático, com implicaçóes negativas para o processo de formação dos alunos de mestrado e doutorado". Isso acaba gerando todo um processo de questionamento sobre a própria ideia de qualidade da pós-graduação, "uma vez que os quesitos e indicadores de qualidade, que vem sendo utilizados, produzem efeitos que parecem modelar negativamente a produção, formação e a própria gestão dos programas de pós-graduação e da pesquisa científica”.

O desafio é, sem dúvida, o equilíbrio entre quantidade e qualidade nos processos avaliativos. Por isso, a solução não está na ausência de avaliação, mas no projeto subentendido e no dimensionamento de suas consequências. Ter um processo de avaliação equilibrado pode significar preocupação em garantir critérios de qualidade orientadores das decisóes nas diferentes esferas institucionais e oferecer para indicadores de qualidade dos programas e dos serviços prestados à sociedade; assim como, fomentar a produção científica, a inserção na comunidade científica e divulgação dos resultados, conforme apontado Oliveira e Fonseca (2010).

O que cabe denunciar é a desvirtuação do processo avaliação no mercado de publicaçóes e fomento a publicaçáo desenfreada e superficial, conforme apontado por Waters (2006). Depois de nove anos da pesquisa de Oliveira e Fonseca (2010) e treze anos da pesquisa de Waters (2006), 
podemos afirmar que a proposta que prevaleceu foi a do livre mercado de produção e publicação científica, da concorrência entre programas, da submissão de docentes e discentes ao produtivismo e da corrida desenfreada pela alimentação do Lattes e citações.

Diante dessa lógica constituem-se de um lado as elites acadêmicas (GUIMARÃES, 2019) instituídas e legitimadas pela autoridade científica, que pela sua posição de destaque usufruem de determinados privilégios no mercado das publicações e dos conceitos; e, de outro, a prostituição da produção do conhecimento diante da lógica da produtividade e performatividade, já exemplificadas nas sessóes anteriores deste artigo (editoras e periódicos predatórios, sobrecarga de trabalho aos docentes, seletividade de discentes iniciados). Desse modo, a excelência é para poucos. $\mathrm{O}$ questionamento é inevitável: somente o 'grupo da excelência' produz com qualidade? A resposta é não. Entretanto, ganham destaque nesse contexto os méritos que desconsideram as desigualdades epistêmicas, sociais e econômicas, em que está assentada a produção do conhecimento.

Por isso, acreditamos que seja urgente e necessário o debate, a pesquisa empírica e a discussão teórica dos próprios programas de pós-graduação para aferir resultados que possam avaliar a produção científica para além das medidas de desempenho, limitadas a critérios quantitativos da produtividade dos docentes, discentes e programa. A avaliaçáo de um programa e de seus pesquisadores não pode ficar refém da suposta qualidade aferida por critérios quantitativos que são estabelecidos a partir de referenciais nem sempre compatíveis com os impactos sociais que a pesquisa deve proporcionar.

\section{Consideraçóes finais}

$\mathrm{O}$ enfrentamento do dilema entre qualidade e quantidade faz parte de todo e qualquer avaliação. A definição de critérios que orientarão os processos, construçáo de instrumentos e geração de resultados é sempre desafiante. A opçáo por critérios quantitativos é inevitável e constitui-se numa métrica importante, no entanto, não pode ser a única e desconsiderar elementos qualitativos inerentes aos processos humanos de formação, pesquisa e trabalho. $\mathrm{O}$ trabalho docente e de pesquisa não segue a mesma 
lógica da produção de objetos de consumo, os produtos e os processos são diferentes, por isso, portadores de lógicas diferentes de produção.

$\mathrm{O}$ produtivismo acadêmico e a cultura da performatividade são o resultado inegável de processos avaliativos da pós-graduação centrados na quantidade desmedida de processos e produtos que operam a partir de outra lógica, que é a da produção do conhecimento. É inegável que a instituição dos processos avaliativos fomentou e impulsionou a produçáo científica, publicaçóes, periódicos e programas de fomento e financiamento. No entanto, impulsionou, também, a ampliação e o fortalecimento dos veículos predatórios e da superficializaçáo dos resultados publicados. Bachelard (1979) há muito chamou a atenção para a adesão fácil à armadilha da conduta da medição e da pesagem como um limitador da criatividade e paciência científica, já que limita o "espírito científico" a pensar somente aquilo que se pode medir e pesar.

Tal modo de compreender os fenômenos satisfaz a curiosidade ingênua e torna-se um empecilho para a criatividade e criticidade científica, já que não há interesse em pesquisas, mas sim em revelar evidências por meio de instrumentos que se constituem um fim em si mesmo. Não é por acaso que Bachelard $(1996$; 1977) define tal postura como um obstáculo epistemológico e um empecilho para o exercício da "vigilância epistemológica". A corrida pelos números e indicadores imprime aos programas e aos seus sujeitos o ritmo frenético da geração de produtos, remodelando e aligeirando os processos formativos nos programas de pós-graduaçãa, o desenho das pesquisas - que precisam ser enxutas e rápidas - e, na mesma proporção, a rapidez pela publicação dos resultados, os quais muitas vezes são fatiados para atender o imediatismo. Somam-se a esses fatores a seletividade discente e o sofrimento psíquico a que estão submetidos muitos docentes e discentes.

O que buscamos mostrar no presente artigo são as evidências de como tal processo impacta na gestão dos programas de pós-graduação e no compromisso social da produção do conhecimento e formação profissional/científica. A denúncia nefasta de tais processos vem de longa data, no entanto, as tentativas de melhorá-lo ou remodelá-lo estão voltadas para o aperfeiçoamento da estratégia da performatividade e competividade. Nesse sentido, a denúncia de muitas vozes e em múltiplos espaços cumpre o papel de fomentar o debate e chamar a atenção social e acadêmica para os riscos da mercantilização da produção do conhecimento. 
O trabalho acadêmico e a pesquisa não têm como fim a publicação em atendimento às métricas de produtividade, esta seria a consequência da produção do conhecimento, porém em época de "reféns da publicação" (BIANCHETTI, MACHADO, 2007) ela se torna o eixo central em torno do qual gravitam os esforços intelectuais. Por isso, o risco anunciado por Bianchetti, Valle e Pereira (2015) do "fim dos intelectuais acadêmicos" é eminente diante da cultura do gerencialismo, performatividade e produtividade e do desmonte das instituições públicas de ensino e pesquisa sob a égide do discurso liberal inovador/modernizador (LAVAL, 2004).

\section{Notas}

1 O método utilizado pelo Prof. Jeffrey Beall para identificar as revistas e editoras predatórias, bem como a lista completa, podem ser acessados em: https://beallslist.weebly.com/

2 Informações obtidas em: < https://predaqualis.netlify.com/>, acesso em 24 de abril de 2109.

3 Disponível em: https://sucupira.capes.gov.br

\section{Referências}

ANDRADE, J.S.; CASSUNDÉ, F. R. S. A.; BARBOSA, M. A. C. Da liberdade à "gaiola de cristal": sobre o produtivismo acadêmico na pós-graduação. Perspectivas em Gestão \& Conhecimento, v. 9, n. 1, p. 169-197, jan./abr. 2019.

BACHELARD, G. O racionalismo aplicado. Rio de Janeiro: Zahar Editores, 1977.

BACHELARD, G. A filosofia do não: filosofia do novo espírito científico. São Paulo: Abril Cultural, 1979.

BACHELARD, G. A formação do espírito científico: contribuiçóes para uma psicanálise do conhecimento. Rio de Janeiro: Contraponto, 1996.

BEALL, J. Predatory publishing is just one of the consequences of gold open access. Learned Publishing, v. 26, n. 2, p. 79-84, 2013.

BIANCHETTI, L.; ZUIN, A.A.S.; FERRAZ, O. Publique, apareça ou pereça: produtivismo acadêmico, "pesquisa administrada" e plágio nos tempos da cultura digital. Salvador: EDUFBA, 2018.

BAINCHETTI, L.; VALLE, I.R.; PEREIRA, G.M. O fim dos intelectuais acadêmicos? Induçôes da Capes, desafios às associaçóes cientificas e a emergência do intelectual institucionalizado. Campinas: Autores Associados, 2015. 
BIANCHETTI, L.; MACHADO, A. M. N. "Reféns da produtividade" sobre produçáo do conhecimento, saúde dos pesquisadores e intensificaçáo do trabalho na pós-graduação. XXX Reunião Anual da ANPEd, 2007.

GUIMARÃES, I. P. Um estudo das elites acadêmicas no campo da política educacional no Brasil. Praxis Educativa, Ponta Grossa, v. 14, n. 1, p. 273-296, jan./abr. 2019.

LAVAL, C. A escola não é uma empresa: o neo-liberalimsmo em ataque ao ensino público. Londrina: Planta, 2004.

MACHADO, A.M.; GROSCH, M.S.; SANTOS V. Regulação e controle na pós-graduação: do produtivismo acadêmico à noção de excelência com pertinência territorial. Conjectura: Filosofia e Educação, v. 22, n. 1, p. 52-68, jan./abr. 2017.

MOREIRA, A. F. A cultura da performatividade e a avaliação da Pós-Graduação em Educação no Brasil. Educação em Revista, v. 25, n. 3, p. 23-42, dez. 2009.

OLIVEIRA, R. L. Órfãos de Jeffrey Beall: revistas predatórias e outras iniciativas igualmente perniciosas para a pesquisa. Ciência e Cultura, Campinas, v. 69, n. 4, p. 4-5, oct./dec. 2017.

OLIVEIRA, J. F. de; FONSECA, M. A pós-graduação e o seu sistema de avaliação. In: OLIVEIRA, J. F. de; CATANI, A. M.; FERREIRA, N. S. C. (orgs.). Pós-graduação e avaliação: impactos e perspectivas no Brasil e no cenário internacional. Campinas: Mercado de Letras, 2010, p.15-51.

SUETH, R.; PAULA, M. F. C. Efeitos das políticas de avaliação sobre o trabalho acadêmico na pós-graduação stricto sensu. Revista Argentina de Educación Superior/ RAES, n. 17, p. 12-26, ag./nov. 2018.

TREIN, E.; RODRIGUES, J. O mal-estar na academia: produtivismo científico, o fetichismo do conhecimento mercadoria. Revista Brasileira de Educação, v. 16, n. 48, set./dez. 2011.

WATERS, L. Inimigos da esperança: publicar, perecer e o eclipse da erudição. São Paulo: Unesp, 2006.

ZUIN, A. A. S.; BIANCHETTI, L. O produtivismo na era do "publique, apareça ou pereça”: um equilíbrio difícil e necessário. Cadernos de Pesquisa, São Paulo, v. 45, n. 158, p. 726-750 out./dez. 2015.

Recebido em 28 jul. 2019 / Aprovado em 2 out. 2019

Para referenciar este texto:

FÁVERO, A. A.; CONSALTÉR, E.; TONIETO, C. A avaliação da pós-graduação e a sua relação com a produção científica: dilemas entre a qualidade e a quantidade. EccoS - Revista Científica, São Paulo, n. 51, eI4508, out./dez. 2019. Disponível em: https://doi.org/I0.5585/EccoS.n5I.I 4508. 